\title{
Notas e novos táxons em Acanthoderini (Coleoptera, Cerambycidae, Lamiinae). IV. Sobre o gênero Oreodera A.-Serville
}

\author{
Maria Helena M. Galileo ${ }^{1,3}$ \& Ubirajara R. Martins ${ }^{2,3}$ \\ ${ }^{1}$ Museu de Ciências Naturais, Fundação Zoobotânica do Rio Grande do Sul. Caixa Postal 1188, 90001-970 Porto Alegre, \\ Rio Grande do Sul, Brasil. \\ ${ }^{2}$ Museu de Zoologia, Universidade de São Paulo. Caixa Postal 42494, 04218-970 São Paulo, São Paulo, Brasil. \\ 3 Pesquisador do CNPq.
}

ABSTRACT. Notes and new taxa on Acanthoderini (Coleoptera, Cerambycidae, Lamiinae). IV. On the genus Oreodera A.-Serville. Oreodera tuberculata Thomson, 1865 is redescribed and recorded for Bolivia. New species described and figured from Brazil: $O$. curiosa sp. nov. (Espírito Santo); O. sensibilis sp. nov., O. tuberculifera sp. nov. and O. triangularis sp. nov. (São Paulo).

KEY WORDS. Oreodera; Neotropical; new species; new record; taxonomy.

RESUMO. Oreodera tuberculata Thomson, 1865 é redescrita e assinalada para a Bolívia. Espécies novas descritas e figuradas do Brasil: O. curiosa sp. nov. (Espírito Santo); O. sensibilis sp. nov., O. tuberculifera sp. nov. e O. triangularis sp. nov. (São Paulo).

PALAVRAS-CHAVE. Oreodera; Neotropical; novas espécies; novo registro; taxonomia.

O gênero Oreodera Audinet-Serville, 1835 é dos mais numerosos e heterogêneos da tribo Acanthoderini e contava com 89 espécies (Monné 2005). Audinet-Serville (1835: 19), já na descrição do gênero, propôs três divisões, cada uma com apenas uma espécie:

"Première division": ápices dos élitros truncados em linha reta, com espinho externo. Espécie incluída, Oreodera glauca (Linnaeus, 1758). "Deuxième division": extremidades elitrais acuminadas. Espécie incluída: Oreodera cinerea Audinet-Serville, 1835. "Troisième division": ápices dos élitros arredondados e desarmados. Espécie incluída: Oreodera pubicornis AudinetServille, 1835, que foi eleita espécie-tipo do gênero Pycnomorphus Thomson, 1864, nome pré-ocupado e denominado por RoguET (2004: 90) Penaherreraus.

Blanchard (1845) apenas mencionou alguns caracteres para definir Oreodera, sem incluir espécies. Whiтe (1855: 348) arrolou nove espécies como integrantes de Oreodera, quatro das quais nomina nuda. Além de O. scabra (Fabricius, 1792), sinônima de O. glauca, incluiu O. quinquetuberculata (Drapiez, 1820) e seu sinônimo O. trinodosa Germar, 1824 e duas espécies de ERICHSON (1847): O. aerumnosa e O. achatina.

Thomson (1860) declarou que sua coleção reunia 12 espécies, sem descrevê-las.

Bates (1861: 15), ao comentar Oreodera, referiu-se aos tubérculos pronotais como organizados em triângulo, entretanto o tubérculo centro-posterior pode faltar ou todos podem estar ausentes. Os tubérculos pronotais, a forma e a convexidade dos élitros serviram de base para a divisão das espécies ocorrentes na Amazônia (BATes 1861):
1. Disco pronotal com três ou dois tubérculos proeminentes; ápices elitrais truncados

.... O. undulata, O. fructuosa, O. glauca, O. bituberculata, O. rufofasciata, O. lacteostragata, O. remota, O. sericata, O. cretata

1 '. Disco pronotal sem tubérculos; élitros menos distintamente,

"sometimes scarce perceptibly, trucated at apex" .......... 2

2. Élitros deprimidos ....................... O. simplex, O. griseozonata

2'. Élitros algo convexos ...(subgênero Anoreina) . O. (A.) nana

THomson (1864) sinonimizou Anoreina (subgênero proposto por BATES 1861) com Oreodera. Em 1865, o mesmo autor, descreveu resumidamente seis espécies. Monné \& Giesbert (1993) revalidaram o gênero Anoreina sem acrescentar comentários.

LACORDAIRE (1872) adotou pela primeira vez a granulação ocular para discriminar os gêneros de Acanthoderini; Oreodera foi incluído entre os gêneros com olhos fortemente granulados, genas muito curtas e antenas dotadas de pêlos no lado interno dos flagelômeros basais; por esse tempo foram constatadas 28 espécies em Oreodera.

Bates (1879-1885) afirmou que 33 espécies de Oreodera haviam sido descritas, das quais 23 ocorrentes no México e na América Central; ignorou as divisões que propôs em 1861.

Autores mais recentes foram incluindo espécies sul-americanas isoladamente: Melzer (1930, 1932), Tippmann (1953, 1960); LANe (1955), Fuchs (1958, 1964), ZajCIW (1963), Villiers (1971), Marinoni \& Martins (1978), Monné \& Fragoso (1988), Martins \& Monné (1993), Galileo \& Martins (1998, 1999) e Martins \& Galileo (2005). Monné (2005) omitiu O. minima Galileo \& Martins, 1999 no seu catálogo. 
Esses autores não utilizaram nenhum dos caracteres usados anteriormente para proceder a uma divisão do gênero, que se faz muito necessária. Todas as espécies possuem olhos grosseiramente granulados, mas podem ser agrupadas segundo o número e posição dos tubérculos pronotais (que podem estar presentes ou ausentes); convexidade dos élitros; grânulos nos élitros; espinho no lado externo dos ápices dos élitros; truncatura do mesosterno; comprimento dos tarsômeros; pêlos laterais na face ventral dos protarsômeros V dos machos. Estes caracteres serão utilizados para procedermos à divisão de Oreodera em artigo que temos em preparação. Por ora, descreveremos mais quatro espécies do Brasil e redescrevemos uma originalmente descrita da Colômbia, registrada para o Equador e agora assinalada para a Bolívia.

As siglas utilizadas no texto correspondem a Museu de Ciências Naturais, Fundação Zoobotânica do Rio Grande do Sul, Porto Alegre, Brasil (MCNZ); Muséum National d'Histoire Naturelle, Paris, França (MNHN); Museu Nacional, Universidade Federal do Rio de Janeiro, Rio de Janeiro, Brasil (MNRJ); Museu de Zoologia, Universidade de São Paulo, São Paulo, Brasil (MZSP); National Museum of Natural History, Washington, Estados Unidos (USNM).

\section{Oreodera tuberculata Thomson, 1865}

Oreodera tuberculata Thomson, 1865: 542; Monné, 2005: 195 (cat.).

Tegumento avermelhado apenas mais escuro na cabeça, escapo e protórax. Cabeça revestida por pubescência amarelada. Antenas atingem o ápice dos élitros, aproximadamente, na metade do antenômero VI. Escapo com alguma pubescência branca no lado interno. Flagelômeros avermelhados revestidos por pubescência amarelada.

Protórax com tubérculo lateral aguçado. Partes laterais do protórax com sulco estreito, transversal à frente do tubérculo. Pronoto com dois tubérculos à frente do meio; pubescência amarelada intercalada pela pontuação fina e abundante, espaço entre os pontos menor que o diâmetro de um ponto.

Élitros revestidos por pubescência castanho-clara com manchas castanho-escuras: mancha junto à margem adiante do meio; uma faixa transversal, da margem à sutura, com bordas irregulares no terço apical e mancha no lado externo das extremidades. Tubérculos agudos, glabros, na base dos élitros e mais concentrados nos úmeros; na metade apical, alguns pontos contrastantes. Extremidades elitrais obliquamente truncadas com espinhos no ângulos marginal e sutural.

Face inferior do corpo com pubescência amarelada. Fêmures com pincéis de pêlos brancos.

Material examinado. Bolívia, Santa Cruz: Cachuela, macho, 1922, W.M. Mann leg., Mulford Biological Exploration (1921-1922) (USNM).

Discussão. Foi examinada a fotografia do holótipo (MNHN) procedente da Colômbia e assinalada para o Equador no catálogo de Monné (2005:195). Registramos a espécie para a Bolívia e como a descrição original é resumida julgamos oportuno redescrevê-la.

\section{Oreodera curiosa sp. nov.}

Fig. 1

Etimologia. Latim, curiosa $=$ estranha.

Tegumento avermelhado. Pubescência corporal amarelada. Lobos oculares superiores tão distantes entre si quanto o dobro da largura de um lobo. Antenas com tegumento avermelhado; antenômeros revestidos por pubescência branco-amarelada.

Protórax com tubérculo lateral arredondado. Pronoto com dois tubérculos muito discretos e transversais no meio; pontuação restrita às fileiras transversais junto às margens anterior e posterior, nesta mais evidente.

Pubescência elitral amarelada com reflexos dourados. Faixa subtransversal de pubescência branca no meio, levemente descendente da margem para a sutura que não chega a alcançar; no interior dessa faixa, encontram-se dois pontos contrastantes com perímetro glabro; bordas anterior e posterior da faixa com tegumento castanho-escuro. Terço anterior dos élitros com pontuação moderada e faixa estreita transversal, dorsal, de tegumento castanho-escuro, aproximada da sutura e distante da margem; quarto apical com faixa transversal, irregular de pubescência acastanhada. Extremidades elitrais obliquamente truncadas e desarmadas.

Face ventral do corpo revestida por pubescência esbranquiçada no centro e amarelada com reflexos dourados nos lados.

Dimensões em milímetros, holótipo fêmea. Comprimento total, 9,8; comprimento do protórax, 1,7; maior largura do protórax, 3,0; comprimento do élitro, 7,4; largura umeral, 3,4.

Material-tipo. Holótipo fêmea, BRASIL, Espírito Santo: Barra do São Francisco (Córrego Itá), XI.1954, W. Grossmann leg. (MNRJ).

Discussão. Oreodera curiosa sp. nov., além do aspecto geral mais compacto, distingue-se de Oreodera tijuca Marinoni \& Martins, 1978 pela faixa de pubescência branca dos élitros, com bordas bem irregulares, que encera dois pontos contrastantes e pela ausência de faixa de pubescência branca, estreita e próxima das extremidade elitrais. Em O. tijuca a faixa branca de pubescência no meio dos élitros envolve área com pubescência amarelo-dourada e o terço apical apresenta faixa estreita, curva de pubescência branca próxima da sutura.

\section{Oreodera triangularis sp. nov.}

\section{Fig. 2}

Etimologia. Latim, triangularis $=$ triangular; alusivo ao formato dos élitros.

Tegumento avermelhado. Cabeça revestida por pubescência amarelada. Lobos oculares superiores com seis fileiras de omatídios, tão distantes entre si quanto mais que o dobro da largura de um lobo. Antenas dos machos atingem o ápice dos élitros na ponta do antenômero VI. Flagelômeros com pubescência esbranquiçada na base e escura no ápice.

Protórax com tubérculo lateral arredondado no topo, precedido por sulco transversal. Pronoto sem tubérculos, com 

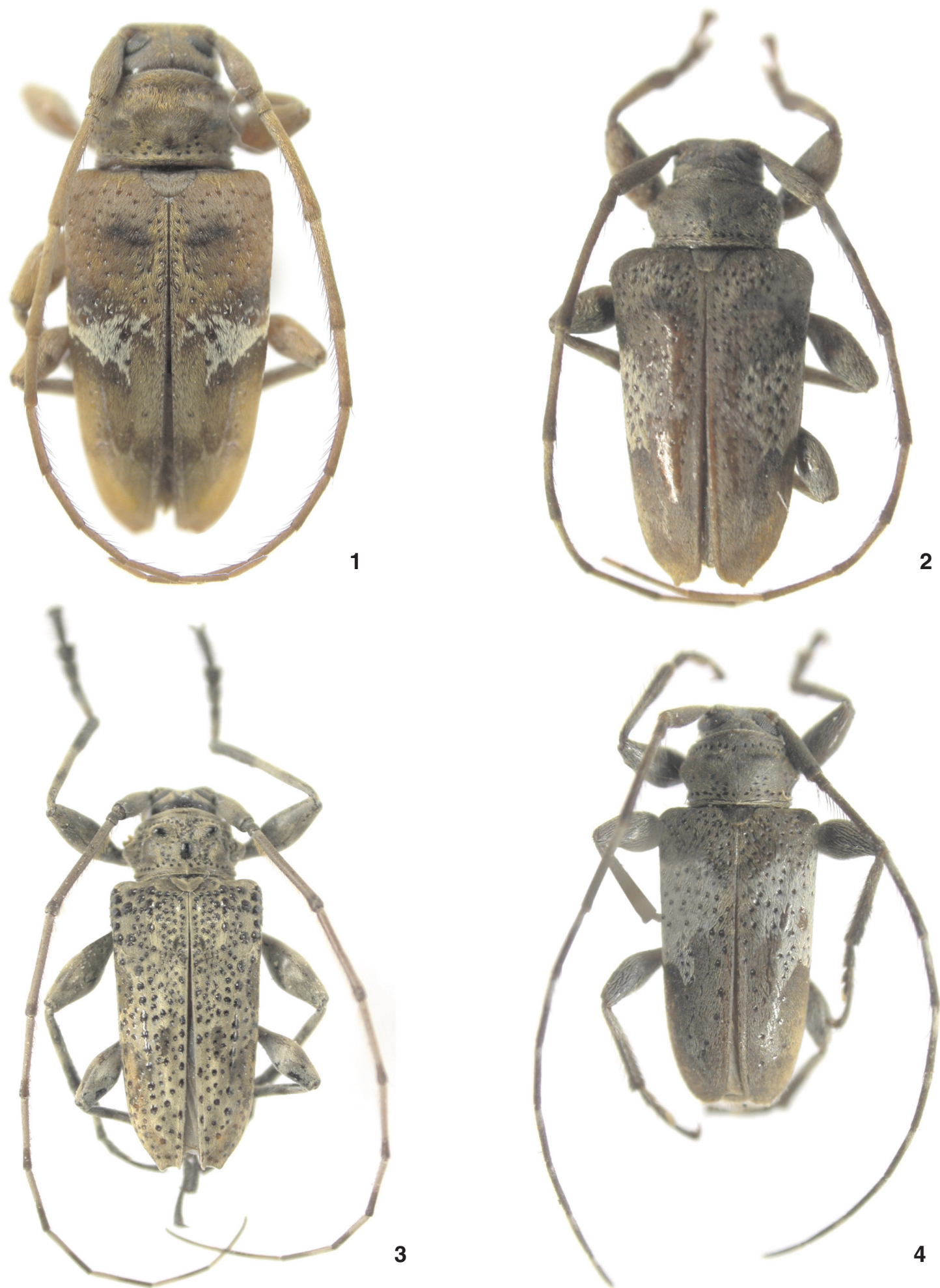

Figuras 1-5. Habitus.(1) Oreodera curiosa sp. nov., holótipo fêmea, 9,8 mm; (2) O. triangularis sp. nov., holótipo macho, 7,5 mm; (3) O. tuberculifera sp. nov., holótipo macho, 16,1 mm; (4) O. sensibilis sp. nov., holótipo macho, 7,1 mm. 
pubescência amarelada uniforme; fileira transversal de pontos adiante da borda posterior; fileira de pontos junto à borda anterior pouco demarcada.

Élitros triangulares em conjunto e revestidos por pubescência predominantemente amarelada. No meio de cada um dos élitros, mancha larga de pubescência branca, subtransversal, com bordas irregulares, que se estende da margem até próximo à sutura. Pontuação elitral presente na metade anterior e contrastante com a pubescência branca; ausente na metade apical. No quarto apical de cada élitro pequena mancha longitudinal de pubescência branca. Extremidades dos élitros com espículo externo.

Face ventral recoberta por pubescência branco-amarelada, mais concentrada nos lados do metasterno. Pernas revestidas por pubescência amarelada; lados dos fêmures e extremidades das tíbias pretos. Profêmures pouco mais desenvolvidos do que os meso- e metafêmures.

Dimensões em milímetros, macho. Comprimento total, 7,5; comprimento do protórax, 1,2; maior largura do protórax, 2,3; comprimento do élitro, 5,6; largura umeral, 3,4.

Material-tipo. Holótipo macho, Brasil, São Paulo: Porto Cabral (Rio Paraná), 15-30.X.1941, L. Travassos Filho leg. (MZSP).

Discussão. Oreodera triangularis sp. nov. assemelha-se a $O$. ohausi Melzer,1930 pelos élitros com mancha larga de pubescência branca. Difere pelos élitros relativamente mais curtos e mais largos; pela ausência de manchas pretas no pronoto; pelos lobos oculares superiores muito distantes entre si; pelo pronoto sem pontos no disco; pelos élitros sem pontos na metade apical e com as extremidades projetadas em espículo no lado externo.

\section{Oreodera tuberculifera sp. nov.}

\section{Fig. 3}

Tegumento castanho-escuro a preto. Cabeça revestida por pubescência amarelada. Lobos oculares superiores com 10-11 fileiras de omatídios, tão distantes entre si quanto a largura de um lobo. Lobos oculares inferiores mais longos que o dobro do comprimento das genas. Antenas dos machos atingem o ápice dos élitros no meio do antenômero VI. Flagelômeros com a região apical escurecida, que gradualmente é mais extensa em direção flagelômeros apicais.

Protórax com tubérculo lateral desenvolvido precedido anteriormente por sulco transversal. Pronoto com pubescência amarelada e três tubérculos manifestos, glabros; pontuação pronotal, além das fileiras de pontos próximos às margens, com outros pontos entre os tubérculos.

Élitros revestidos por pubescência amarelada com manchas de pubescência acastanhada: uma lateral, distante da sutura e unida estreitamente pela margem a outra mancha situada no terço apical; dorsalmente, atrás do meio, mancha pequena. Pontuação elitral muito abundante e presente em toda a superfície; na base, para os lados dos úmeros, os tubérculos são grandes e prolongam-se até o meio constituindo uma fileira oblíqua. Extremidades elitrais obliquamente truncadas com dois espinhos curtos nos ângulos.
Fêmures revestidos por pubescência amarelada. Tíbias amareladas com as extremidades pretas. Metade basal dos mesoe metatarsômero I com pubescência branca. Face ventral coberta por pubescência acinzentada. Mesosterno truncado anteriormente.

Dimensões em milímetros, macho. Comprimento total, 14,5-19,4; comprimento do protórax, 2,5-3,4; maior largura do protórax, 4,6-6,3; comprimento do élitro, 11,5-14,5; largura umeral, 5,3-7,6.

Material-tipo. Holótipo macho, BrasiL, São Paulo: Cubatão, 9.I.2007, H. Ramos leg. (MZSP). Parátipos: São Paulo: Itanhaém, 17.X.1956, V. Cajado leg. (MZSP); Praia Grande, macho, 15.01.1997, Mermudes leg. (MZSP); Santos, 3 machos, J. Metz leg. (MZSP, MCNZ); São Sebastião (Ilha da Vitória), macho, 24.III6.IV.1965, Expedição do Departamento de Zoologia leg. (MZSP).

Discussão. Todos os exemplares foram coligidos em pequena área do litoral do Estado de São Paulo entre São Sebastião e Itanhaém.

Oreodera tuberculifera sp. nov. assemelha-se a O. pustulosa Monné \& Fragoso, 1988, pelos grânulos dos élitros. Difere pelo padrão de colorido dos élitros, sem áreas cobertas por pubescência esbranquiçada e pelos grânulos elitrais mais numerosos. Difere de O. charisoma Lane, 1955 pelas menores dimensões e pelo maior número de grânulos na base dos élitros.

\section{Oreodera sensibilis sp. nov.}

Fig. 4

Etimologia. Latim, sensibilis = sensível, incomum, estranha.

Tegumento corporal castanho-avermelhado, mais escuro na cabeça, no protórax e nas pernas. Cabeça revestida por pubescência amarelo-esbranquiçada. Lobos oculares superiores com seis ou sete fileiras de omatídios; tão distantes entre si quanto a largura de um lobo. Antenas do macho atingem o ápice do élitro na extremidade do antenômero VII. Flagelômeros com pubescência esbranquiçada na base.

Protórax com tubérculo lateral rombo. Pronoto com duas elevações, transversais, anteriores, muito discretas; fileiras de pontos junto às orlas anterior e basal; três ou quatro pontos atrás dos tubérculos laterais e nos lados da base.

Cada élitro com mancha de pubescência esbranquiçada que não atinge, mas aproxima-se da sutura, localizada à frente do meio; bordas anterior e posterior dessa mancha, irregulares, aquela menos denteada do que esta; restante da superfície com pubescência amarelada. Pontuação grossa, distinta, na metade anterior e muito esparsa na metade apical dos élitros. Extremidades elitrais arredondadas.

Fêmures revestidos por pubescência esbranquiçada. Profêmures mais robustos que os meso- e metafêmures. Face ventral do corpo revestido por pubescência branco-amarelada.

Dimensões em milímetros, holótipo fêmea. Comprimento total, 7,1; comprimento do protórax, 1,3; maior largura do protórax, 2, 1; comprimento do élitro, 5,3; largura umeral, 2,8. 
Material-tipo. Holótipo macho, BrasiL, São Paulo: Embu, 9-10.II.1974, F. Lane leg. (MZSP).

Discussão. Oreodera sensibilis sp. nov. assemelha-se a $O$. sericata Bates, 1861, mas se distingue pelos tubérculos pronotais sem pêlos; pela ausência de traço de pubescência branca na base dos élitros; pela presença de alguns pontos na metade apical dos élitros e pela área coberta por pubescência branca que se inicia próxima do quinto basal. Em O. sericata os tubérculos pronotais são encimados por pêlos; não existem pontos na metade apical dos élitros e a área de pubescência branca dos élitros inicia-se perto dos úmeros.

\section{AGRADECIMENTOS}

Aos curadores das coleções que cederam material para estudo; a Eleandro Moysés (MCNZ), pela execução das fotografias.

\section{REFERÊNCIAS BIBLIOGRÁFICAS}

Audinet-Serville, J.G. 1835. Nouvelle classification de la famille des longicornes (suite). Annales de la Société Entomologique de France (1) 4: 5-100.

Bates, H.W. 1861. Contributions to an insect fauna of the Amazon Valley. Coleoptera: Longicornes. The Annals and Magazine of Natural History (3) 8: 40-52; 147-152; 212219; 471-478.

BAtes, H.W. 1879-1885. Biologia Centrali-Americana, Insecta, Coleoptera, Longicornes. British Museum of Natural History, vol. 5, 436p.

BLANCHARD, C.E. 1845. Histoire des insectes, traitant de leurs moeurs et de leurs métamorphoses en général, et comprenant une nouvelle classification fondée sur leurs rapports naturels. Didot, vol. 2, 524p.

ERICHSON, W.F. 1847. Conspectus insectorum coleopterorum quae in Republica Peruana observata sunt. Archiv für Naturgeschichte 13: 67-185.

Fuchs, E. 1958. 3. Beitrag zur Kenntnis der neotropischen Cerambyciden. Koleopterologische Rundschau 36: 52-61.

Fuchs, E. 1964. 6. Beitrag zur Kenntnis der neotropischen Cerambyciden. Koleopterologische Rundschau 42: 6-10.

Galileo, M.H.M. \& U.R. Martins. 1998. Novo gênero e novas espécies de Lamiinae neotropicais. Revista Brasileira de Entomologia 42 (3/4): 147-153.

Galileo, M.H.M. \& U.R. Martins. 1999. Sobre espécies de Lamiinae da Colômbia e do Brasil com garras tarsais divaricadas. Papéis Avulsos de Zoologia 41 (6): 83-104.

LACORDAIRE, J.T. 1872. Histoire Naturelle des Insectes. Genera des Coléoptères, ou exposé méthodique et critique de tous les genres proposés jusqu'ici dans cet ordre d'insectes. Librairie Encyclopédique de Roret, vol. 9 (2), p. 411-930.

Lane, F. 1955. Cerambycoidea Neotropica nova III. Papéis Avulsos de Zoologia 12(13): 281-296.

Marinoni, R.C. \& U.R. Martins. 1978. Notas sinonímicas e novas espécies em Acanthoderini. Papéis Avulsos de Zoologia 31(11): 173-193.
Martins, U.R. \& M.H.M. Galileo. 2005. Cerambycidae (Coleoptera) da Colômbia. VII. Novos táxons, novos registros, nova sinonímia, nova combinação e novo nome, Revista Brasileira de Zoologia 22(1): 5-18.

Martins, U.R. \& M.A. Monné. 1993. Novas espécies de Oreodera A.-Serville, 1835 e Alphus White, 1855 (Acanthoderini). Iheringia, Série Zoologia (74): 133-140.

Melzer, J. 1930. Longicórneos do Brasil, novos ou pouco conhecidos II. Archivos do Instituto Biológico de Defesa Agricola e Animal 3: 187-208.

Melzer, J. 1932. Novos gêneros e novas espécies de cerambycideos do Brasil. Revista de Entomologia 2 (4): 420434.

Monné, M.A. 2005. Catalogue of the Cerambycidae (Coleoptera) of the Neotropical region. Part II. Subfamily Lamiinae. Zootaxa 1023: 1-759.

Monné, M.A. \& S.A. Fragoso. 1988. Novas espécies e sinonímia de Oreodera Audinet-Serville, 1835 (Acanthoderini). Revista Brasileira de Biologia 48 (4): 811-831.

Monné, M.A. \& E.F. Giesbert. 1993. Cheklist of the Cerambycidae and Disteniidae (Coleoptera) of the Western Hemisphere. Wolfsgarden Books, 410p.

Roguet, D. 2004. Penaherreraus nomen nov. pro Pycnomorphus Thomson, 1864 (nec Motschulsky, 1858) (Coleoptera, Cerambycidae, Lamiinae). Le Coléoptériste 7(2): 90.

Thomson, J. 1860. Essai d'une classification de la famille des cérambycides et materiaux pour servir a une monographie de cette famille. 404p.

Thomson, J. 1864. Systema cerambycidarum ou exposé de tous les genres compris dans la famille des cérambycides et familles limitrophes. Mémoires de la Société Royale des Sciences de Liège 19: 1-540.

Thomson, J. 1865. Diagnoses d'espèces nouvelles qui seront décrites dans l'appendix du systema cerambycidarum. Mémoires de la Société Royale des Sciences de Liège 19: 541-578.

Tippmann, F.F. 1953. Studien über neotropische Longicornier II. Dusenia 4: 313-362.

Tippmann, F.F. 1960. Studien über neotropische Longicornier III. Koleopterologische Rundschau 37-38: 82-217.

VilLiers, A. 1971. Cerambycidae récoltés en Guyane Française par la mission du Muséum National d'Histoire Naturelle. Annales de la Société Entomologique de France (N. S.) 7 (2): 343-350.

White, A. 1855. Catalogue of the coleopterous insects in the collection of the British Museum. Longicornia, 2. London, British Museum of Natural History, vol. 8, p. 175-412

ZajcIW, D. 1963. Novos Longicórneos neotrópicos IX. Revista Brasileira de Biologia 23 (4): 421-428.

Recebido em 30.III.2007; aceito em 20.VII.2007. 